\title{
OS HÁBITOS ALIMENTARES DURANTE O PRIMEIRO CONFINAMENTO DERIVADO DA PANDEMIA PROVOCADA PELA COVID-19 - REVISÃO DA LITERATURA
}

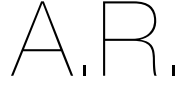
ARTIGO DE REVISÃO

${ }^{1}$ Faculdade de Farmácia da Universidade de Coimbra,

Pólo das Ciências da

Paúde,

Azinhaga de Santa Comba 3000-548 Coimbra, Portugal

`Endereço para correspondência:

Miguel José Correia Fialho Faculdade de Farmácia da Universidade de Coimbra, Pólo das Ciências da Saúde, Azinhaga de Santa Comba, 3000-548 Coimbra, Portuga mgfialho8@gmail.com

Histórico do artigo:

Recebido a 22 de março de 2021 Aceite a 13 de agosto de 2021

\section{EATING HABITS DURING THE FIRST CONFINEMENT CAUSED BY THE COVID-19 PANDEMIC - LITERATURE REVIEW}

Inês Alexandra Figueiredo de Almeida'; Miguel José Correia Fialho1; Maria João Campos'; Angelina Pena'

RESUMO

A infeção pelo vírus SARS-CoV-2, identificada pela primeira vez na China, rapidamente se difundiu a nível mundial. A fim de diminuir a propagação desta doença infeciosa, declarada como uma pandemia, foram decretados confinamentos domiciliários um pouco por todo o mundo. Estes confinamentos alteraram os hábitos alimentares da população, na maioria dos casos para pior, verificando-se um aumento no consumo de alimentos menos saudáveis. Este fator e a diminuição da atividade física verificada, podem culminar no desenvolvimento de patologias metabólicas, cardiovasculares e outras. Assim, é essencial alertar as populações neste sentido e educá-las para melhores escolhas alimentares.

\section{PALAVRAS-CHAVE}

Alimentação, Confinamento, COVID-19, Pandemia, SARS-CoV-2

\section{ABSTRACT}

The COVID-19 disease, first identified in China, quickly spread worldwide. In order to reduce the spread of this contagious disease, declared as a world pandemic, some governments decreed home confinement. These confinements changed the eating habits of the population, in their majority for worse, with an increase in the consumption of unhealthy foods. This factor and the decrease of physical activity can conduce to the development of metabolic, cardiovascular and other pathologies. Therefore, it is essential to alert populations in this regard and educate them for better food choices.

KEYWORDS

Food, Lockdown, COVID-19, Pandemic, SARS-CoV-2

\section{INTRODUÇÃO}

O novo coronavírus SARS-CoV-2 foi reconhecido pela primeira vez, como causa de um surto de pneumonia viral incomum, em dezembro de 2019, na China, na cidade de Wuhan (1). Em fevereiro de 2020, após vários estudos do vírus e depois de se perceber que era possível a transmissão entre humanos, a Organização Mundial da Saúde (OMS), denominou a doença provocada por este vírus de COVID-19 (1). A rápida disseminação desta infeção viral por vários países em todo o mundo e a evolução no número de novos casos diários nos mesmos países fez com que a OMS, a 11 de março de 2020, declarasse esta doença como uma pandemia (2). Rapidamente, foram adotadas medidas de contenção da propagação do vírus a nível mundial. Em Portugal, foi decretado o estado de emergência em todo o território nacional com confinamento domiciliário e isolamento social entre 19 de março e 2 de maio de 2020 (3). Adicionalmente, por todo o mundo, ao longo de 2020 foram declarados vários confinamentos, a fim de evitar uma elevada propagação da doença, diminuindo o contágio, a mortalidade e a sobrecarga dos serviços de saúde (4). Este confinamento deu origem a uma nova realidade, que embora tenha sido vivenciada de maneiras diferentes por todo o mundo, modificou os hábitos alimentares da população em geral (5-10). Assim, torna-se importante perceber quais as alterações nos hábitos alimentares a nível mundial durante este período e quais as suas implicações, quer a nível da saúde individual quer a nível da saúde das populações. É também importante alertar as populações neste sentido e dar-Ihes informação para poderem optar por escolhas alimentares mais equilibradas e saudáveis.

\section{METODOLOGIA}

As publicações que sustentam esta revisão foram pesquisadas entre os dias 10 e 31 de outubro de 2020, no motor de busca "PubMed" usando os descritores "(food and covid-19 and (confinement or lockdown))" em simultâneo e publicados entre outubro de 2019 e outubro de 2020. A partir da pesquisa realizada, dos 168 artigos identificados, foram selecionados pelos autores 5 artigos para a elaboração desta revisão da literatura, de acordo 
com o seu grau de interesse, pertinência, relevância em relação ao tema a abordar e também tendo em consideração o maior impacto da revista onde os mesmos foram publicados. Uma vez que a realidade portuguesa era de todo o interesse, foi pesquisado no site oficial da Direção-Geral da Saúde (DGS), no separador Documentos e Publicações, o inquérito que retratasse esta realidade.

Os Hábitos Alimentares Durante o Primeiro Confinamento em Portugal

\section{Inquérito REACT-COVID}

O inquérito online e telefónico "Inquérito sobre alimentação e atividade física em contexto de contenção social" realizado pela DGS em Portugal foi respondido por 5874 pessoas, com idade igual ou superior a 16 anos, entre 9 de abril e 4 de maio de 2020 (5).

Dos inquiridos, $45,1 \%$ responderam ter alterado os seus hábitos alimentares, sendo que destes, 58,2\% alteraram os seus hábitos para melhor. As principais alterações visaram um aumento de 31,1\% no consumo de água, de 30,9\% no consumo de snacks doces, de $29,7 \%$ no consumo de frutas e de $21,0 \%$ no consumo de hortícolas. Por outro lado, ocorreu uma diminuição de $43,8 \%$ no consumo de take-away, de 40,7\% no consumo de refeições pré-preparadas, de $32,8 \%$ no consumo de refrigerantes e de $28,2 \%$ no consumo de bebidas alcoólicas. Nos comportamentos associados à alimentação, $71 \%$ dos inquiridos alteraram o número de idas às compras, 56,9\% passaram a cozinhar mais, $31,4 \%$ passaram a petiscar mais ao longo do dia e 30,1\% alteraram o número de refeições diárias. Em relação ao peso, $26,4 \%$ dos portugueses percecionaram um aumento, ao contrário de 16,3\% que percecionou uma diminuição do seu peso. Este questionário concluiu que, quase metade dos inquiridos alteraram a sua alimentação durante o confinamento embora mais de metade não tenha registado alterações no seu peso (5).

\section{Inquérito da Associação DECO}

Um dado interessante foi obtido por um inquérito da associação DECODefesa do consumidor, que verificou que em abril de 2020, período de confinamento, apenas $19 \%$ dos consumidores deitaram comida fora contra $56 \%$ que assumiram deitar para o lixo alimentos que consumiam em casa, no inquérito realizado entre janeiro e fevereiro, período pré-isolamento. Este questionário contou com a resposta de 833 portugueses, entre os 30 e os 74 anos (11).

\section{Os Hábitos Alimentares Durante o Confinamento em Espanha} Inquérito Food Choice and Cooking Attitudes in Spain

$\mathrm{O}$ inquérito online "Consumer behavior in confinement times: Food choice and cooking attitudes in Spain" foi conduzido, durante a sexta semana de confinamento, de 19 a 25 de abril de 2020, permitindo ter uma noção da variação dos hábitos alimentares durante o confinamento. Este inquérito, teve como amostra as respostas de 600 pessoas com idades compreendidas entre os 18 e os 68 anos de idade, das quais $50,1 \%$ mulheres (6).

Como resultado pode-se constatar que, aproximadamente 50\% afirmaram um consumo similar, antes e durante o confinamento, das diferentes categorias alimentares com exceção da fruta, do pescado e dos doces. Contudo, uma percentagem importante de consumidores teve a perceção de se estar a alimentar de forma diferente; mais de $33 \%$ reconheceram uma diminuição no consumo de pescado e mais de $50 \%$ um aumento no consumo de doces, o que pode indicar um deterioramento dos hábitos alimentares. Com base nos dados os inquiridos foram separados em três grupos, (na =172, nb =264, nc=164), dois dos quais com um maior envolvimento e mais gosto na atividade de cozinhar, "a" e "c", e um outro completamente contrastante "b", considerando o facto de cozinhar mais um dever do que um prazer. O grupo "a" distingue-se do "c" através dos hábitos alimentares, escolhendo alimentos mais saudáveis e evitando os alimentos ultra processados. Pelo contrário, os elementos do grupo "c" foram caracterizados pelo facto de consumirem mais alimentos densamente energéticos, como snacks e produtos alimentares ultra processados, provavelmente devido a um estado emocional mais deprimido, segundo os autores.

Apesar do confinamento ter deteriorado a qualidade da alimentação, mais de $20 \%$ dos inquiridos manifestaram a intenção de continuar a cozinhar e mais de $15 \%$ disse que pretende manter e melhorar os hábitos alimentares saudáveis, como o maior consumo de produtos hortofrutícolas (6).

\section{Inquérito COVIDiet Study}

O principal objetivo deste estudo foi avaliar se ocorreram alterações nos comportamentos alimentares da população espanhola adulta, estudando se houve uma maior ou uma menor adesão à Dieta Mediterrânica. Desta forma, foi efetuado um inquérito online, reportando as três primeiras semanas do confinamento, mais concretamente entre 13 de março e 3 de abril de 2020, com 7514 participantes, 37\% com idade menor que 35 anos, 70,6\% mulheres (7). Para poder ocorrer uma comparação a nível de alterações na dieta, foi estabelecida como dieta saudável ideal a Dieta Mediterrânica, dieta baseada na Roda dos Alimentos Mediterrânica, no consumo de frutas e produtos hortícolas da época e de azeite, também reconhecida por melhorar o sistema imunitário.

Com base nos dados foi possível identificar três grupos, de acordo com a adesão à Dieta Mediterrânica: baixa ( $n=2447$ vs. $n=1275)$, média $(n=3773$ vs. $n=4129$ ), elevada ( $n=1294$ vs. $n=2110$ ) (antes vs. durante o confinamento, respetivamente). No grupo de indivíduos com maior adesão à Dieta Mediterrânica foi possível identificar um decréscimo do consumo de doces, snacks, bebidas açucaradas e/ou com gás, e do consumo diário de carnes vermelhas entre 16\% e 18\%, e um acréscimo diário de aproximadamente $12 \%$ no consumo de fruta e produtos hortícolas. Segundo os resultados do inquérito, o consumo de álcool diminuiu em cerca de 57\%, na população inquirida.

Concluindo, 45\% dos inquiridos (3392 dos 7514) demostraram a intenção de aderir à Dieta Mediterrânica, o que pode ter um impacto positivo na saúde dos indivíduos.

\section{Os Hábitos Alimentares Durante o Confinamento na Europa} Inquérito ELP-Covid-19

O inquérito online "Everyday life praxis COVID-19 (ELP-COVID-19)" foi conduzido na Europa onde também se observou uma alteração nos hábitos alimentares durante o confinamento provocado pela COVID-19. Este estudo contou com a resposta de 4108 pessoas, $62,8 \%$ das quais mulheres, com idades compreendias entre os 15 e os 82 anos e foi feito em 9 países: Bósnia e Herzegovina (2,2\%), Croácia (40,1\%), Eslováquia (12,9\%), Eslovénia (10,8\%) e Espanha (7,6\%), Grécia (2,4\%), Itália (12,5\%), Kosovo (2,6\%), Sérvia (8,9\%), entre 15 de abril e 3 de maio de 2020 (8).

Durante o confinamento, no que toca às refeições, $44 \%$ dos participantes adotaram hábitos alimentares com refeições mais regulares contra 16\% que fizeram menos refeições regulares; $29 \%$ dos participantes aumentaram a quantidade de comida no prato enquanto $20 \%$ diminuíram esta quantidade; $33 \%$ dos participantes aumentaram o consumo de alimentos não saudáveis (por exemplo, doces e fast food) contra $35 \%$ que relataram uma redução no 
consumo de alimentos não saudáveis. Por sua vez, menos de 10\% dos participantes aumentaram o consumo de álcool e tabaco contra $36 \%$ que beberam menos e $14 \%$ que fumaram menos.

Adicionalmente, 2208 participantes relataram um aumento de 0,3 kg na sua massa corporal. Segundo os autores do artigo, este aumento pode ser explicado em 20,6\% com o aumento do tamanho das refeições e da realização de uma alimentação não saudável e também com o aumento do tempo de utilização de equipamentos eletrónicos e da diminuição da atividade física.

\section{Os Hábitos Alimentares Durante o Confinamento no Mundo Inquérito ECLB-COVID19}

O inquérito online "Effects of home Confinement on multiple Lifestyle Behaviours during the COVID-19 outbreak (ECLB-COVID19)" realizado a nível mundial elucida, que de uma maneira geral, os hábitos alimentares pioraram durante o confinamento dos vários países devido à COVID-19. Este inquérito, teve em consideração as primeiras 1047 respostas dadas, todas de maiores de 18 anos, sendo $54 \%$ delas de mulheres, com respostas da Ásia Ocidental (36\%), do Norte de África (40\%), da Europa (21\%) e de outros países (3\%) e decorreu entre 6 e 11 de abril de 2020 (9).

Quando resumidos, os principais resultados deste inquérito relatam que apesar do consumo de bebidas alcoólicas ter diminuído (5,4\% vs. $10,1 \%$ para às vezes, $1,2 \%$ vs. $1,8 \%$ para maior parte das vezes e $0,2 \%$ vs. 0,4\% para sempre) (durante vs. antes do confinamento, respetivamente), o consumo de alimentos e os padrões de refeição tornaram-se menos saudáveis. Houve um aumento no consumo de alimentos menos saudáveis, mais densamente energéticos e ricos em açúcar e/ou gorduras e pobres em fibras e vitaminas, como por exemplo, batatas fritas, bolos e molhos (23,3\% vs. $18,4 \%$ para maior parte das vezes e 10,9\% vs. 6,2\% para sempre) (durante vs. antes do confinamento, respetivamente), na gula ou no ato de comer desenfreadamente $(20,4 \%$ vs. 9,7\% para maior parte das vezes e $9,6 \%$ vs. $2,3 \%$ para sempre) (durante vs. antes do confinamento, respetivamente), nos snacks entre refeições (24,4\% vs. $13,9 \%$ para maior parte das vezes e $15,4 \%$ vs. 6,4\% para sempre) (durante vs. antes do confinamento, respetivamente) e no número de refeições principais durante o confinamento $(14,5 \%$ vs. $6,6 \%$ para 4 refeições principais, $6,3 \%$ vs. $2,4 \%$ para 5 refeições principais e $2,8 \%$ vs. $0,8 \%$ para mais de 5 refeições principais) (durante vs. antes do confinamento, respetivamente) (9).

Inquérito Online a Adolescentes da Itália, Espanha, Chile, Colômbia e Brasil

Este inquérito online, efetuado em 5 países de dois continentes, demonstrou que o confinamento influenciou os hábitos alimentares das populações desses países. Este inquérito contou com a participação de 820 adolescentes, todos entre os 10 e 19 anos, dos quais faziam parte $61,1 \%$ de raparigas, sendo jovens do Brasil $(14,02 \%)$, do Chile (26,22\%), da Colômbia (19,63\%), da Espanha (18,54\%) e da Itália (21,59\%), sendo que as respostas foram obtidas entre 17 de abril e 25 de maio de 2020 (10).

Os resultados mostram que, durante o confinamento, houve um aumento no consumo de leguminosas, produtos hortícolas e fruta. O consumo de 2 porções de leguminosas por semana passou dos $22,7 \%$ para $25 \%$, o consumo de produtos hortícolas todos os dias passou dos $35,2 \%$ para os $43 \%$ e o consumo de pelo menos uma peça de fruta por dia passou dos $25,5 \%$ para os $33,2 \%$, durante o confinamento. Verificou-se também uma drástica diminuição no consumo de fast food, já que, durante o confinamento ocorreu um aumento de $20 \%$ dos inquiridos que consumiram fast food menos de uma vez por semana. No entanto, o consumo de fritos e doces aumentou neste período, por exemplo, no caso dos doces, a percentagem de jovens que consumiram doces todos os dias passou dos $14 \%$ para os $20,7 \%$ (10).

\section{Causas das Alterações dos Hábitos Alimentares Durante o Primeiro Confinamento Derivado da COVID-19}

Em Portugal, a DGS apurou que as principais causas para as alterações nos hábitos alimentares culminavam em 3 eixos. $01 .^{\circ}$ eixo, e o mais importante, está relacionado com o confinamento e as alterações dos horários de trabalho e o modelo de compras que este impôs, o $2 .^{\circ}$ eixo mais relacionado com o stress vivenciado e as alterações de apetite e, finalmente, o $3 .^{\circ}$ eixo relacionado com receios de alterações na situação económica (5). Resumidamente, a alteração das idas às compras afetou 34,3\% dos inquiridos, sendo que, 10,6\% foram afetados pela alteração do local onde habitualmente compram alimentos; não obstante 19,3\% reportaram uma alteração do apetite, sendo que 18,6\% referenciaram o stress como indutor de alteração do mesmo; 17,6\% afirmaram que as alterações no horário de trabalho também provocaram perturbações (5).

Apesar de 56,9\% dos portugueses ter começado a cozinhar mais (possivelmente resultado do maior tempo em casa e do menor acesso a comida confecionada fora); 31,4\% admitiram ter começado a petiscar mais ao longo do dia, existindo desta forma um consumo aumentado de snacks, uma vez que, estes proporcionam sensação de conforto e recompensa (5).

A relação entre a alimentação e o novo coronavírus não alterou o padrão de consumo dos portugueses, já que $76 \%$ dos inquiridos indicaram que não começaram a comprar ou consumir alimentos específicos passíveis de proteção contra o SARS-CoV-2 (5).

Um outro ponto importante foi o risco de insegurança alimentar, "situações onde o acesso ao alimento é reduzido, inadequado do ponto de vista nutricional ou até inexistente" (12), que foi de 32,3\% durante o primeiro confinamento em Portugal. Neste âmbito, 33,7\% dos inquiridos reportaram preocupação ou incerteza quanto ao acesso aos alimentos por dificuldades económicas e 8,3\% reportaram dificuldades económicas no acesso aos alimentos (5).

Nos restantes estudos mencionados, quer na Europa, quer no Mundo, as causas mais relevantes invocadas para as alterações nos hábitos alimentares consistiram no aumento do tempo passado em casa, o que implicou um aumento do tempo passado a cozinhar, do tempo a ver televisão, do sedentarismo, do tédio e também do stress. Contudo, também implicou uma diminuição das idas ao restaurante e das idas ao supermercado culminando numa dificuldade ao acesso de alimentos frescos (6-10).

\section{DISCUSSÃO DOS RESULTADOS/CONCLUSÕES}

É notório que, durante o período de confinamento domiciliário, causado pela pandemia derivada da doença transmitida pelo vírus SARS-CoV-2, os hábitos alimentares da população a nível mundial sofreram alterações. Na maior parte dos estudos mencionados, a população reportou hábitos alimentares menos saudáveis durante o período de confinamento (6-10).

O confinamento domiciliário e o isolamento social são de extrema relevância para diminuir os contágios comunitários. No entanto, a nível de hábitos alimentares, nos países onde houve um aumento no consumo de alimentos/refeições menos saudáveis, a saúde da população pode ficar gravemente afetada após a pandemia, uma vez que, nestes países aliado a piores hábitos alimentares houve uma diminuição da prática de 
atividade física e consequentemente um aumento do comportamento sedentário (5, 7-9). Estes dois fatores conjugados podem vir a ser uma causa de alterações metabólicas, como o aparecimento/agravamento da obesidade (13) e da diabetes (13), e do aparecimento/agravamento de doenças cardiovasculares, com potencial impacto num futuro próximo (14). De notar que estas doenças foram associadas a piores sintomas, a um pior prognóstico e a uma maior mortalidade entre doentes com COVID-19 (15). De outra forma, a procura de informação sobre a pandemia poderá ser um fator de desequilíbrios alimentares, uma vez que, pode levar ao aparecimento de angústia, ansiedade e depressão normalmente associados ao consumo de alimentos de conforto, ou seja, alimentos não saudáveis nos quais se incluem alimentos com elevado teor de gordura e açúcares (12).

É de salientar os casos particulares dos países europeus, como por exemplo Portugal e Espanha, nos quais houve uma alteração dos hábitos alimentares para melhor (5-8) e um aumento da adesão à Dieta Mediterrânica (7). Ademais, verificou-se uma diminuição global do consumo de bebidas alcoólicas (5, 7-9) e um aumento do consumo de fruta e produtos hortícolas em adolescentes (10). No entanto, é essencial atentar nas consequências económicas que podem advir da pandemia e que colocarão em causa esta tendência, nomeadamente por uma dificuldade financeira na aquisição de alimentos saudáveis.

É importante realçar que embora não haja nenhum alimento diretamente relacionado com a diminuição do contágio ou com uma melhoria direta dos sintomas causados pela doença COVID-19 sabe-se que, uma alimentação apropriada e um bom estado nutricional são fundamentais para prevenir e minimizar as consequências desta infeção viral e melhorar o sistema imunitário $(12,15)$.

Posto isto, é importante garantir que em futuros confinamentos domiciliários deverá existir um maior acesso e uma maior divulgação de informação sobre como conseguir uma alimentação mais variada e saudável e uma prática regular de exercício físico, mesmo em casa. Esta divulgação deve ocorrer quer por parte das entidades nacionais e internacionais responsáveis, quer por parte dos profissionais de saúde. Uma das responsabilidades destes é o aconselhamento para uma alimentação variada, saudável, equilibrada e nutricionalmente consistente. Uma recomendação prática, eficaz e facilmente exequível pela população, passa por cumprir a ordem das refeições. São aconselháveis 6 a 7 refeições diárias e, para além disso, o pequenoalmoço, almoço e jantar não devem ser negligenciados. Noutra vertente, o profissional de saúde deve aconselhar a prática regular do exercício físico e a manutenção das rotinas, incluindo a do sono que também não deve ser descuidada assumindo um papel importante no estado de saúde do indivíduo, quer físico, quer psicológico.

As recomendações visam aconselhar que na ida às compras é fundamental evitar comprar alimentos supérfluos e de baixa qualidade nutricional, substituindo-os por alimentos ricos em nutrientes. Para isso, é essencial fazer uma lista de compras, com base na ementa planeada das refeições semanais, evitando o desequilíbrio entre os alimentos frescos e não frescos e a ingestão de alimentos desnecessários e, principalmente, adequando esta lista ao orçamento familiar disponível. Para além destas recomendações é também essencial definir um espaço para trabalhar e um espaço para a refeição, e fazer as refeições em horários determinados, nunca saltando refeições.

Seguramente, o aumento do tempo passado em casa pode ser uma mais valia para incutir na população escolhas alimentares mais saudáveis e variadas, tais como as sustentadas pela Dieta Mediterrânica.

\section{REFERÊNCIAS BIBLIOGRÁFICAS}

1. Hu B, Guo H, Zhou P, Shi Z-L. Characteristics of SARS-CoV-2 and COVID-19. Nat Rev Microbiol [Internet]. 2020 Oct 6; Available from: http://dx.doi.org/10.1038/ s41579-020-00459-7.

2. Adhanom T. WHO Director-General's opening remarks at the media briefing on COVID-19 [Internet]. World Health Organization. 2020 [cited 2020 Oct 29]. Available from: https://www.who.int/dg/speeches/detail/who-director-general-s-opening-remarks-at-the-media-briefing-on-covid-19---11-march-2020.

3. Presidente da República. Decreto do Presidente da República 14-A/2020, 2020-0318 - DRE [Internet]. Diário da República n.o 55/2020, 3o Suplemento, Série I. 2020. Available from: https://dre.pt/web/guest/home/-/dre/130399862/details/maximized. 4. Alwan NA, Burgess RA, Ashworth S, Beale R, Bhadelia N, Bogaert D, et al. Scientific consensus on the COVID-19 pandemic: we need to act now. Lancet [Internet]. 2020 Oct;396(10260):e71-2. Available from: https://linkinghub.elsevier.com/retrieve/ pii/S014067362032153X.

5. Direção-Geral da Saúde. REACT-COVID - Inquérito sobre alimentação e atividade física em contexto de contenção social. 2020;1-15. Available from: www.dgs.pt. 6. Romeo-Arroyo E, Mora M, Vázquez-Araújo L. Consumer behavior in confinement times: Food choice and cooking attitudes in Spain. Int J Gastron Food Sci [Internet]. 2020 Oct;21:100226. Available from: https://linkinghub.elsevier.com/retrieve/ pii/S1878450X20301037.

7. Rodríguez-Pérez C, Molina-Montes E, Verardo V, Artacho R, García-Villanova B, Guerra-Hernández EJ, et al. Changes in Dietary Behaviours during the COVID-19 Outbreak Confinement in the Spanish COVIDiet Study. Nutrients [Internet]. 2020 Jun 10;12(6):1730. Available from: https://www.mdpi.com/2072-6643/12/6/1730.

8. Pišot S, Milovanović I, Šimunič B, Gentile A, Bosnar K, Prot F, et al. Maintaining everyday life praxis in the time of COVID-19 pandemic measures (ELP-COVID-19 survey). Eur J Public Health [Internet]. 2020 Dec 11;30(6):1181-6. Available from: https:// academic.oup.com/eurpub/article/30/6/1181/5880552.

9. Ammar A, Brach M, Trabelsi K, Chtourou H, Boukhris O, Masmoudi L, et al. Effects of COVID-19 Home Confinement on Eating Behaviour and Physical Activity: Results of the ECLB-COVID19 International Online Survey. Nutrients [Internet]. 2020 May 28;12(6):1583. Available from: https://www.mdpi.com/2072-6643/12/6/1583.

10. Ruiz-Roso MB, de Carvalho Padilha P, Mantilla-Escalante DC, Ulloa N, Brun P, Acevedo-Correa D, et al. Covid-19 Confinement and Changes of Adolescent's Dietary Trends in Italy, Spain, Chile, Colombia and Brazil. Nutrients [Internet]. 2020 Jun 17;12(6):1807. Available from: https://www.mdpi.com/2072-6643/12/6/1807.

11. Carvalho BMS. Inquérito sobre desperdício de alimentos _ DECO PROTESTE [Internet]. 2020 [cited 2020 Oct 29]. Available from: https://www.deco.proteste.pt/ casa-energia/consumo-sustentavel/noticias/pandemia-leva-portugueses-a-desperdicarem-menos-alimentos?fbclid=IWAR15UU_q5Mz1mn4UI9DGPkrlmuDx6MnJ_bYBQ9Lnp_Wq9tn505gpQS-ardE\#.

12. João Gregório M, Irving S, Teixeira D, Mendes de Sousa S, Ferreira B. Manual de Intervenção Alimentar e Nutricional. 2020;1-81. Available from: www.dgs.pt.

13. Khan MA, Moverley Smith JE. "Covibesity," a new pandemic. Obes Med [Internet]. 2020 Sep;19:100282. Available from: https://linkinghub.elsevier.com/retrieve/ pii/S2451847620301020.

14. Peçanha T, Goessler KF, Roschel H, Gualano B. Social isolation during the COVID-19 pandemic can increase physical inactivity and the global burden of cardiovascular disease. Am J Physiol Circ Physiol [Internet]. 2020 Jun 1;318(6):H1441-6. Available from: https://journals.physiology.org/doi/10.1152/ajpheart.00268.2020. 15. Chaari A, Bendriss G, Zakaria D, McVeigh C. Importance of Dietary Changes During the Coronavirus Pandemic: How to Upgrade Your Immune Response. Front Public Heal [Internet]. 2020 Aug 27;8:4-12. Available from: https://www.frontiersin.org/ article/10.3389/fpubh.2020.00476/full. 